\title{
Pharmacists: The Guardians of Safe Medication Use
}

\author{
Régis Vaillancourt
}

$\mathrm{I}^{\mathrm{n}}$ $\mathrm{n}$ this issue of the CJHP, $\mathrm{Al}$ Hamarneh and others ${ }^{1}$ report an interesting study in which they assessed hospital pharmacists' own perceptions of their role. The study involved asking hospital pharmacists in Alberta, "What does a pharmacist do?" The majority of responses referred to activities that focused on either drugs or drug distribution; only a minority of responses related to patient-centred activities. The authors conclude that hospital pharmacists may not have fully embraced the concept of patient-centred care as outlined in the Blueprint for Pharmacy. ${ }^{2}$

I concur that it is important for hospital pharmacists to focus their practice on patient care. However, I would argue that the perception on the part of hospital pharmacists that their role focuses on drug distribution, as reported by $\mathrm{Al} \mathrm{Hamarneh}$ and others, does in fact align with the essential requirements of providing pharmaceutical care. This sentiment is reflected in the vision of the Blueprint for Pharmacy, ${ }^{2}$ as well as the Basel consensus statements on hospital pharmacy issued by the International Pharmaceutical Federation (FIP). ${ }^{3}$

In 1992, Strand and others ${ }^{4}$ stated that the pharmacy services required to provide pharmaceutical care should include timely and accurate drug distribution, timely and complete patient data, comprehensive and current drug information, and documentation of pharmacists' decisions and interventions. Eighteen years later, I believe that these pharmacy services remain fundamental to practice. Indeed, the benefit of providing advanced clinical pharmacy services is lost if the element of "timely and accurate drug distribution" is missing and the patient does not receive the correct medications. This point of view has been validated more recently by a CSHP advocacy campaign $^{5}$ and an address at the 2007 Annual Meeting of the American College of Clinical Pharmacy (ACCP). ${ }^{6}$

The June 2008 CSHP advocacy campaign focused on optimal drug distribution and its impact on patient safety. A key message of that campaign was that "Safe, accurate, well-designed and efficient drug distribution systems are critical to safe patient care". Inclusion of drug distribution as part of the selfperceived role of a hospital pharmacist does not negate or contradict the concept of patient-centred care. This argument is also supported by the remarks of Koda-Kimble during the 2007
ACCP conference. KodaKimble stressed that as we strive to expand our scope of practice into the realm of patient-focused care, we must maintain our core responsibility as stewards of medication management systems and ongoing quality assurance. ${ }^{6}$ She cited the example of an institution whose clinical

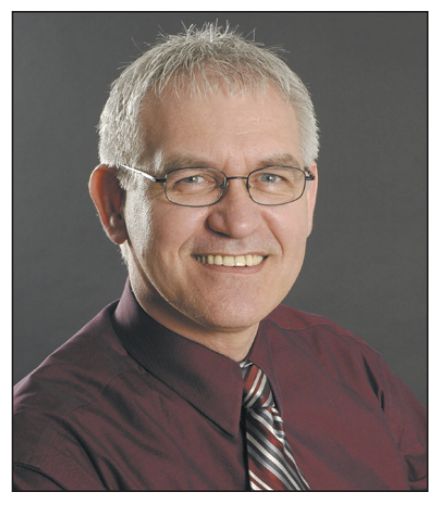
and operational pharmacists were practising in organizational "silos", which resulted in unacceptable medication management practices and an overall decrease in the integrity of the drug distribution system. ${ }^{6}$

The Blueprint for Pharmacy vision statement- "optimal drug therapy outcomes for Canadians through patient-centred care"2-is undoubtedly focused on patients. However, the Blueprint does not suggest that the profession of pharmacy neglect its responsibilities for drug distribution. In fact, the Blueprint document states that pharmacists and pharmacy technicians have a dual mandate to protect the safety, security, and integrity of the drug distribution system and to lead the development of, and to participate in, medication safety initiatives. ${ }^{2}$ The study by Al Hamarneh and others indicates that hospital pharmacists are defining their role through an essential element of care: the right dose of the right drug, given to the right patient at the right time by the right route-in other words, the drug distribution system.

The FIP's Basel consensus statements on hospital pharmacy practice 3 support enhanced patient care activities for pharmacists, but they also support pharmacists' role as custodians of the medication management system. In fact, some of the consensus statements directly support putting pharmacists in charge of the drug distribution system: "Health authorities and hospital administrators should engage hospital pharmacists in all steps in the hospital medicines-use process" and "Hospital pharmacists should take responsibility for all medication logistics in hospitals". ${ }^{3}$ These statements clearly delineate the role of hospital 
pharmacists within the drug distribution system, in addition to their clinical activities.

The requirements to practise pharmaceutical care, the Blueprint for Pharmacy, and the FIP's Basel consensus statements all support having pharmacists run effective drug distribution systems to support safe patient care. Although drug distribution should not be the sole focus of hospital pharmacy practice, it is a necessary component that does not negate or replace the provision of patient-centred care. Although there may be a need for hospital pharmacists to become further involved in providing patient care, they must not forget their role as stewards of medication management systems as they embrace this expanded scope of practice.

\section{References}

1. Al Hamarneh YN, Rosenthal M, McElnay JC, Tsuyuki RT. Pharmacists' perceptions of their professional role: insights into hospital pharmacy culture. Can J Hosp Pharm 2011;64(1):31-35.

2. Blueprint for Pharmacy: the vision for pharmacy. Ottawa (ON): Canadian Pharmacists Association; 2008 [cited 2010 Dec 17]. Available from: www.pharmacists.ca/content/about_cpha/whats_happening/cpha_in_action/ pdf/BlueprintVision.pdf

3. FIP Global Conference on the Future of Hospital Pharmacy: final Basel statements. The Hague (Netherlands): International Pharmaceutical
Federation (FIP); 2008 Dec 4 [cited 2010 Nov 30]. Available from: www.fip.org/files/fip/HPS/Basel2008/FinalBaselStatements.pdf

4. Strand LM, Cipolle RJ, Morley PC. Pharmaceutical care: an introduction. Kalamazoo (MI): The Upjohn Company; 1992.

5. Medication safety enhanced by drug distribution-2008 [advocacy campaign]. Ottawa (ON): Canadian Society of Hospital Pharmacists; 2008 [cited 2010 Nov 30]. Available from: www.cshp.ca/advocacy/ campaigns/medSafety_e.asp

6. Koda-Kimble issues challenge. Parker Medal winner calls for action through contributions to ACCP Research Institute. ACCP Rep 2007;26(11):8-9.

Régis Vaillancourt, OMM, CD, BPharm, PharmD, FCSHP, is Director of Pharmacy with the Children's Hospital of Eastern Ontario, Ottawa, Ontario. He is also an Associate Editor of the CJHP.

\section{Address correspondence to:}

Dr Régis Vaillancourt

Children's Hospital of Eastern Ontario

401 Smyth Road

Ottawa ON K1H 8L1

e-mail: RVaillancourt@cheo.on.ca

\section{ON THE FRONT COVER}

\section{Mont-Tremblant Park, Quebec}

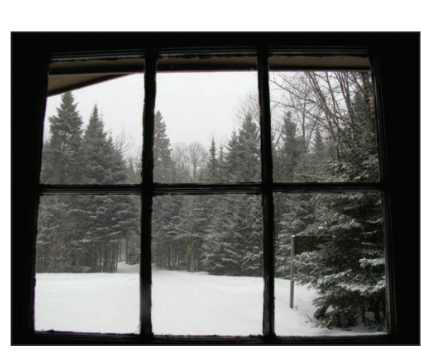

This picture was taken during a cross-country ski trip to the Diable Sector of Mont-Tremblant Park, Quebec, in February 2010. The scene of pine trees and snow was captured from the interior of Ravage Hut. The photographer was Caroline
Cheng, a pharmacist working in Ottawa. She used a Canon PowerShot SX110 camera.

The CJHP would be pleased to consider photographs featuring Canadian scenery taken by CSHP members for use on the front cover of the journal. If you would like to submit a photograph, please send an electronic copy (minimum resolution $300 \mathrm{dpi}$ ) to Colleen Drake at cdrake@cshp.ca. 